\title{
Evaluating the Sciences and Islamic Education Textbooks of the Secondary Level in Jordan in Light of Modern Standards of the Educational Environment
}

\author{
Ibrahim Na ${ }^{`}{ }^{1,{ }^{1}}{ }^{*}$ \& Omar Salim Al-Khateeb ${ }^{1}$ \\ ${ }^{1}$ Department of Education Sciences, World Islamic Sciences \& Education, Amman, Jordan \\ *Corresponding author: Department of Education Sciences, World Islamic Sciences \& \\ Education, Amman, Jordan. E-mail: hash_mored@yahoo.com
}

Received: September 26, 2014 Accepted: November 27, 2014 Published: June 2, 2015

doi:10.5296/ije.v7i2.6360 URL: http://dx.doi.org/10.5296/ije.v7i2.6360

\begin{abstract}
This study aimed to evaluating the textbooks of sciences and Islamic education of the secondary level in Jordan based on the modern standards of educational environment, and the study tried to answer the following questions:

-What are the modern standards of the educational environment that should be available in the books of sciences and Islamic education of the secondary level in Jordan?

- What is the compatibility degree of the textbooks of sciences and Islamic education of the secondary level with the modern standards of the educational environment?

The study sample consisted of the same study population; it's the textbooks of sciences and Islamic education of the secondary level Released by the Ministry of Education for the academic year 2012/2013 AD. And to achieve the objectives of the study, the Researchers have developed a tool to measure and analyze included seven axes and twenty-seven contemporary standards to the environmental education at the secondary level. The tool was presented to committee of specialists to make sure of its sincerity, Extraction reliability coefficient using (Holsti) stability equation, so the reliability coefficient reaching over time $90.1 \%$ ) and by individuals (86.9\%), which is acceptable for the purposes of the study, and this was as an answer to the first question of the study.
\end{abstract}

Keywords: curricula, Islamic education, textbooks, evaluation, science education. 


\section{Introduction \& Theoretical Frame}

The previous century witnessed a great interest of having solutions to the educational problems locally and internationally because of the great effect of these problems in people's life. Some of these problems are pollution, depletion of the natural resources and population explosion beside other problems which were resulted from of the human unconscious behavior towards the environment, This dangerous escalation has been a source of concern in the scientific institutions and therefore, the interest of the planners and the developers of the curricula have increased in the environmental education and this interest focused on the following two basic points:

1- Growing awareness of the role played by the appropriate and healthy environment in human survival.

2- The trend towards updating and developing the school curricula to make them more related to the human current and perspective issues to make sure of a high degree of the learners' participation in solving these problems(Tantawi, 2000)

The extreme behavior towards the environment which the world suffered from, resulted from the technological and industrial progress, the accelerated social changes especially in the developing countries which affect negatively the individual and the family as well as the problems resulted of these situations( shonaq, 2001) plus their social and psychological effects in the individuals' behavior and therefore the educational and religious institutions are obliged to face these effects and treat their causes(Hijazi, 1995).

The educational field is considered one of the most important fields that contribute to cope with the problems of society, dealing with the extreme behavior and finding the appropriate solutions through an organized educational system (Wright, 1980).

The Islamic curricula are important for its role in building the integrated character of the students who care of others' happiness and luxury as these curricula are based on the human and his relation with God and the human and his relation with the environment where he lives. These curricula aimed at developing the individual's thought, organizing his emotions and behaviors according to the Islamic religion and preparing him to adapt to the social and natural environment.

And for the importance of the Islamic curricula as they are considered the basic component in the students' cognitive structure's elements represented by acquiring facts, principles, theories generalizations plus developing the students' thinking skills and raising their ethical level, there should be much attention given to these curricula for their significant role in the students' behavior as the spiritual dimension is the first motivator for this behavior. Additionally, the religious knowledge is also considered a reference for thinking and standards (Al-Dahir, 1993).

Based on this, the impact of Islamic education textbooks' role is seen clearly in treating the students as they are the basic component in the society and so these textbooks need further 
changes and development(Al-alawi, 1988) as the curricula's ignorance of the students' status and being unable to meet their needs, make the students feel worry( Al-Shafi, 1984).

And may be one of the development's aspects of the curricula and the modern trends these days is the environmental education which is considered a pattern of education that organizes the human's relations with his natural, social and psychological environment aiming at providing the learners with educational experience about the characteristics, concepts, thinking methods, attitudes and specific values of the environmental problems in addition to the rights and environmental duties that guide the individual's positive and efficient behavior towards the available environmental resources and therefore, making constructive decisions towards protecting the environment from pollution and waste becomes one of the significant feature of the rational environmental behavior(Motaw, 2001).

Environment defined as everything that surrounds the human directly or indirectly including all the activities that affect human being (UNESCO, 1968). And it is defined comprehensively as (water and social resources) in any place and time to fulfill the human needs and his perspectives (Al-Hamad \& Al-Sabareeni, 1979).

The environment is the place where the human lives and gets the major basics of his life as (food, clothes and shelter plus communications with others). It is the place where the creatures live and it could be dividing into types:

Biosphere: Allah creates it, and the social environment: the individual and society make it, and the environment is pure if environmental balance (Ecology Balance) happened between biological and social environment (Abdel Alathem, 1999).

Environment, although there were many definitions, but the researchers argue that it does not depart from the overall meaning as the overall framework in which live human an influential and influenced by and it consists of living components as( human, animal and plant) and other non-living components as (Atmosphere, Hydrosphere, Lithosphere). Based on these definitions of environment, the researchers concluded the following dimensions:

- Natural dimension: including the different environmental factors and their systems and relations with the surrounding areas.

- Social and economic dimension: including the positive and negative effects of human's activities in utilizing the natural resources.

- Ethical and moral dimension: Includes cultural and ethical dimensions Carried out by the human in the exploitation of the environment resources and the impact positively or negatively on the quality of life in the universe on the quality of life and in the possibility of the environmental systems' stability in a way that is compatible with survival of life. The ethical dimension includes also the current generation's responsibility towards the coming ones by creating a qualitative integrated environment with the least limit of risks that lead to negative changes in the environment. 
- Pollution: The pollution and the depletion of natural resources, population explosion, and sanitation and factories waste are considered problems which the world suffers from as a result of civilized, technological and industrial progress, the separated social changes and the human's irresponsible activities towards environment especially in the developing societies which affect negatively the humanity's destiny (Shnaq, 2001; Salama, 2006; Ghanim, 1997)

Realizing the danger of the environmental problems, many conferences were held as the United Nations Conference On The Human Environment in Stockholm in 1972 and the conference of improving the environment in Dubai and these conferences came up with some recommendations was the need for a comprehensive deep ambitious reform addresses the goals audited, and methods of teaching and methods to renew it, and the teacher is adding to his training and raises would and instils in the mind of the learner and earn basic life skills that help to protect and preserve the environment. (UNEP) (Benign et al., 2000). (UNESCO, 1978).

What is happening from the abuses of the environment makes it imperative we need to Environmental education of our children to be able to protect the environment and the maintenance of its resources, and the imperative need for generations to create environmental awareness Configure positive trends towards it, and review the emotional fabric of the individual composition, and his view of the development of the environment and to deal with them and with their resources rationally; because the most important factor in human contamination and breach of the it and he is the one who is greatly influenced by the disastrous effects of pollution.

\subsection{Environmental education concept \& its philosophy}

In light of the international trends, the definitions of environmental education varied as Belgrade's conference (1975) defined it: "the process that develops information, realization and the attitudes and it creates the individual responsibility regarding the human's relation to his social culture and biophysical environment (UNESCO, 1970).

While" Tableasi's" conference defined it as: "re-guiding the educational experiences to understand the problems in an integrated manner and the rational participation in avoiding the environmental problems and improve the environment's quality(Gillet,1977).

And Stedile(1977) defined the environmental education as: " the educational process that highlights the human relation with his natural and local environment plus the relation of the problems of pollution, resources, technology to the comprehensive humanitarian environment. And Stapp(1978) defined it as Environmental education, saying: It is meaningful to the organization process of human development concepts and skills, attitudes and values and patterns needed to understand the interrelationship between man and his environment behavior And take appropriate decisions concerning the environment and solving existing problems and wor to prevent the emergence of new environmental problems.

Teaching environmental education should address three aspects: teaching about the environment, and the objectives of this aspect of knowledge focused on gathering information, and teaching from the environment. This aspect aims to use the environment as a source of 
Teaching, and education for the environment, it is learning with environmental method, which focuses on the development of conscious attention to the environment, and this side requires the learner's participation for the sake of developing values that guided his behavior (Salem, 1976).

The environmental education represents one of the important axes of the curriculum of Islamic education textbooks which resulted from the human's wrong practices in his environment. It is a process of developing and improving the individual's attitudes, concepts, skills plus changing attitudes towards the natural resources. Islam educates his followers environmentally through teaching the students a set of healthy values which aim to correct the wrong healthy behaviors to prevent diseases, for example, Islam in its application of the principles of "Tahara" ( purity) assured it's invitation to have a clean environment; keeping houses, roads and food clean away from pollution.

Prophet Muhammad ( peace be upon him )- "God is good and loves good, clean and loves cleanliness, generous loves generosity, bounteous loves generosity, Clean up - I see - said: courtyard not resemble the Jews." Narrated by Tirmidhi.

From the above it is clear that environmental education was the result of the growing and deepening dangers that human faced in his modern time, as a result of erroneous behavioral practices and lack of environmental awareness, It is based on building perceptions, skills and attitudes needed to understand and appreciate the complex relations between the human and his or her own vital surroundings and natural values, and training on decision-making on environmental problems, and explains the inevitability of preserving the environment sources and the need for proper exploitation for the benefit of human, in order to preserve his life and raise the standard of living .

It is necessary to pay much attention to the environmental education and to plan and teach the curricula of Ministry Of Education according to it so as to prepare a learner who understands his environment and participates positively to overcome problems and reduce risks and this what was mentioned in the International Conference of Education(2001) which sent an invitation to update the school's curricula and its content taking into account the social changes especially what is related to human rights, spreading forgiveness, ensuring the appropriateness of the school curricula to the educational innovations locally, nationally and internationally in order to build an international humanitarians civilization that based on understanding as a mean for the common living (Mona and Hisham, 2002).

So as to prepare an educated and because the educational philosophy from which educational curricula in Jordan is in a range of goals set by Article IV of the Education Law No. (3) for the year 1994 comes in the forefront of "opening up to what in human cultures of values and attitudes benign And appreciation of humanitarian rights, the formation of values and positive attitudes towards self and others, and work and social progress and represent the principles and values of democracy in the individual and social behavior, and accept the student's self, respect for others, and observance their feelings, and appreciation of their advantages and their achievements (Education Act, 1994). Therefore). So we note a clear harmony between the educational philosophy in Jordan and advocated by the Islamic religion and this is why the 
researchers to make sure of the extent to which science books and Islamic culture at the secondary level in Jordan that are taught in the academic year 2012/2013 contemporary environmental standards.

\section{Problem \& Questions of the Study}

- Note researchers shortcomings in science books and Islamic culture at the secondary level in Jordan in terms of the degree of observance contemporary standards of environmental education, and this is what caused them to be reviewed in order to assess the environmental standards in, therefore, the aim of this study is to assess the science books and Islamic culture. At the secondary level in Jordan that are taught in the academic year 2012/2013 m on the basis of contemporary standards for Environmental Education, where most of the studies carried out - and returned to the researchers - were mostly belong to the science curriculum, social studies and the researchers did not inform on the studies entitled evaluate the books of Islamic education in the light of contemporary environmental standards. The study tries to answer the following two questions:

1- What are the modern standards of the environmental education that should be available in the books of sciences and Islamic education of the secondary level in Jordan for the year 2012/2013.

2- What is the compatibility degree of the books of sciences and Islamic education of the secondary stage in Jordan for the year 2010/2013 with the modern standards of the environmental education?

\section{Significance of the Study}

The significance of the study is represented by the following:

1. Designing instrument to study the contemporary environmental education standards and multiple fields is useful for both researchers and stakeholders in general education curriculum the curriculum of Islamic education in particular, to take advantage of them in the analysis and evaluation and development of curricula and books of Islamic education process

2. This study presents a systematic analysis of the reality of the contemporary environmental standards that required to the curriculum of Islamic education books, for the benefit of educators in the development or amendment.

3. This study reveals the strengths and weaknesses in the curricula and books of Islamic Sciences and the current culture of Islamic high school in Jordan in dealing with global standards for Environmental Education. 


\section{Limitations of the Study}

We can disseminate the results of this study in the light of the following parameters:

1. - the selected spatial and temporal it is to analyze and evaluate of the Islamic Sciences and Islamic culture books at the secondary level in Jordan that are taught in the academic year 2012/2013.

2- Procedural specified and it is represents in the degree of reliability and validity study reached by researcher's instrument, in addition to the user's statistics in the analysis of the results of the study type.

3. Objective results.

\section{Procedural Definitions}

Environmental axis: environmental dimension, which consists of contemporary standards for Environmental Education, which must ensure that in the books of Islamic science and Islamic culture at the secondary level in Jordan that are taught in the academic year 2012/2013

Environmental education: a set of knowledge, values, attitudes and appropriate environmental practices that should be available in the content of the textbooks of Islamic sciences, culture for the secondary stage in Jordan to aware the learners, and strengthen their interest in the environment.

Contemporary standards for Environmental Education: The standard paragraphs of researchers drawn from the world of modern educational trends, and through fact-finding research and studies related to the environmental education. These paragraphs were translated in the instrument researchers presented the arbitrators of experienced and competent in education, curriculum and the environment.

Evaluation of science books and Islamic culture at the secondary level in Jordan: analysis Islamic science and Islamic culture content at the secondary level in Jordan that are taught in the academic year 2012/2013 to determine the amount guaranteed with the contemporary standards for Environmental Education using the prepared tool for that.

Are the books of Islamic Sciences and Islamic culture that are taught in the 11th grade, secondary grade in secondary education in the academic year (2012/2013): The number of four books, which include the following units: (Unit Holy Quran and its sciences, unit Hadith and its sciences, and the unity of the Islamic faith, the unity of the Prophet's biography, and the unit of the civilization Islamic and the present Muslim world, and the unit of the Islamic system, the unit of Islamic jurisprudence).

\section{Significance of the Study}

The importance of this study in the following: 
1. Statement degree of contribution of science books and Islamic culture at the secondary level in Jordan to instill in students the skills to deal with the environment and life in the community in which they live.

2. Design the instrument study on environmental standards and its multiple fields, benefiting researchers and stakeholders educational curricula in general and the curricula of religious studies in particular in the analysis, evaluation, and development of curricula and books of Islamic Studies. Of the seriousness of the growing problems of the environment process, realizing the United Nations adopted this issue, where an international conference in Stockholm in 1972 resulted in the establishment of the United Nations Program for Environment (UNEP) (hamedh and other, 2000).

3. This study discovered the strengths and weaknesses in the books of Islamic science and culture of the current high school in Jordan to achieve contemporary environmental standards reveal.

\section{Previous \& Related Studies}

The researchers briefed on a range of studies on the evaluation of textbooks and curricula in the light of contemporary environmental standards these studies have focused mostly on the evaluation books Social and Science Studies, In the light of contemporary environmental standards while the researchers did not reach any study on the evaluation of Islamic sciences and Islamic education books at the secondary level in Jordan in light of contemporary environmental standards. but these studies varied by the researchers that could access them regarding the evaluation of Islamic Education books to several areas, however, they have benefited in the preparation of the study tools and discuss the results.

The following is a presentation of some studies on Islamic curricula and other analysis in the light of contemporary environmental standards and other standards.

1. Al-Boseidi's study (2003) This study aimed to evaluate Islamic education books at secondary schools in the (Sultanate of Oman) in the light of contemporary issues, and the results showed that the most important contemporary issues facing the Omani society and must be considered when building Islamic education curriculum content in secondary education and social issues of spinsterhood, And the high cost of dowries and encourage cooperative societies, as one of the images of social solidarity and risk resulting from the use of modern technologies, "TV and online information network" and issues of globalization and confront extremist ideas.

2. Qasim's study (2005) aimed to evaluate the curricula of the Islamic education in UAE in dealing with issues as extremism, fanaticism and terrorism. The results showed that the objectives of the curricula include issues that treated extremism, fanaticism and terrorism for example, the Muslim's behavior and modeling this behavior through dealing with others. The results also showed the curricula's interest of preventing the students' involvement in extremism, fanaticism and terrorism plus the curricula 
presented Islamic concepts and ideas that assured the good behavior with those do not have the same opinions, gender, race and the belief.

The study of Hareb(2006) aimed to study of changing Arab educational curricula and its impact on politicians and educators and sociologists considered the study that changing Arab educational curricula is a compressive strength on the politicians. Educators, social scientists, and its extended to all prevailing in Arab countries systems including political systems, the study stated that the project posed US Secretary of State (Colin Powell). About the change in the Arab world as an extension of previous projects to change the Arab regimes, as the study found that the introduction of new concepts such as human rights, civil society and the empowerment of women and the rights of minorities was based on the UNESCO conference in 1998. About higher education, and these concepts it must be entered in accordance with the vision of combining Privacy global cultural and contemporary. The study refuted an accusation Arab education to bear the primary responsibility for incubation terrorists and held that the existence of the concepts of jihad and war and justice is essential under the current circumstances so that it is taught in accordance with the Islamic law.

And Matalqa's study (2007) aimed to study developing the textbooks of Islamic education for the high basic stage in light of the current situations and the population of the study consisted of all the textbooks of Islamic education for the high basic stage for the years 1993-2006. While the sample of the study, which consisted of textbooks of the $8^{\text {th }}$ and the $10^{\text {th }}$ grades over these years, was selected purposefully. The researcher prepared an instrument to analyze the content consisting of five major fields: thinking, dialogue, ethical education, education technology and self-learning.

The study found the following results: The need to develop Islamic Education Textbooks according to the development issues of the day and its innovation. The introduction of thinking skills in the books of Islamic Education. Interest in the field of educational technology in the books of Islamic education through attention to its principles relating to the observance of individual differences among the educated, and diversify the expertise provided by the learner, and attention to quality richness activities so that they are content, and take into account the execution time.

Displaying the previous studies, we find that some of the studies addressed the modern issues as extremism and fanaticism as the studies of(Awad,1993'Al-Alawi, 2001; Al- osaedi, 2003; Qasem, 2005; Hareb, 2006) and other studies addressed the social and the religious values included in the textbooks of Islamic education as the studies of (Jaradi, 1993; Jabr, 1995; Abo-latifa, 1999; Matalqa, 2007) while other studies addressed the modern issues as the studies of ( Dahbor, 2006 \& Salaheen, 2003).

Second: studies addressed evaluating the textbooks of science and social education

Tamlyia's study (1986) aimed at analyzing the content of the textbooks of the science and social education in the primary stage in Jordan in terms of their inclusion of the environmental concepts and a proposed list of the environmental concepts was prepared to be included in the 
textbooks of the science and the social education. And the study concluded that the students' level's achievement of these concepts was less than required level.

In Bahrain, Zaid(1988) conducted a study aimed to identify whether the topics of the textbooks for the primary and basic stages in Bahrain included environmental concepts and attitudes and to identify whether these topics take into account the environmental entrance or not. The researcher analyzed the textbooks using Stab model for the environmental education which included 75 environmental concepts to identify the environmental concepts which these textbooks include and the researcher also used UNESCO list for the environmental attitudes including 11 environmental attitudes to identify the environmental attitudes which these textbooks include. And the study also showed that the environmental concepts were not taking into account in presenting the issues mentioned in the science textbooks for the primary and secondary stages. And Skiker'study (1988) aimed at analyzing the content of the textbooks of geography curricula for the secondary stages in the field of the environmental education. The results showed the curricula objectives paid attention to the natural and human resources more than paying attention to the environment and its problems and maintenance. And the results also revealed the students' positive attitudes towards the environment. The study recommended reconsidering the aims and the content of the geography textbooks in the field of the environmental education through preparing an environmental education that provides a variety of evaluative exercises about the environment.

Marashda's study (1989) aimed to identify the impact of including the environmental dimension in teaching the social studies on the students' attitudes towards the environment. The results revealed statistical significant differences in the students' attitudes towards the environment attributed to the teaching method. The study also recommended including the environmental dimension in the curricula of the social studies and the necessity of conducting further studies on other samples and on different educational stages.

Brody's study (1991) aimed at identifying pollution concepts which are related to the curricula of natural science and the social studies which the $4^{\text {th }}, 8^{\text {th }}$ and $11^{\text {th }}$ grade students have. The students were interviewed to identify their pollution concepts. The study determined the students' correct and wrong concepts. The study concluded that knowledge and the positive values towards Earth are considered one of the major factors in changing the behavior and the $11^{\text {th }}$ grade students' concepts' level is more complicated than the $8^{\text {th }}$ graders' level while the $8^{\text {th }}$ grades students' level was higher than the $4^{\text {th }}$ grade students' level.

In 1995, Hirsh's study aimed to analyze textbooks in terms of the standards and the aims of the environmental education. The results showed that the textbooks did not follow the standards and the description of the new school book and it showed the availability of 26 environmental concepts out of the concepts which were identified in the list of analyzing the content. The study recommended the necessity of having the environmental dimension in the curricula. While Todt's study (1996) aimed to investigate the environmental culture of Ohio Mid and North teachers. The study tried to answer the following questions 'What is the environmental education? And how it can be achieved individually or be measured in a reasonable method? The sample which was consisted of 54 teachers was selected randomly from different eight 
regions representing mid and south of Ohio. The results revealed the teachers' low level of identifying the environmental principles and systems in addition to their low degree of realizing the importance of energy in the natural and the environmental systems.

Qasim's study (2001) aimed to identify the extent of the availability of the environmental education concepts in the textbooks of Arabic for the basic stage in Jordan. The researcher built a list of the environmental educational concepts that suit the basic stage's learners. And the study recommended enhancing the concepts of the environmental education in Arabic curricula.

Al -sawafi's study (2002) aimed at identifying the environmental values in the text books of geography for the basic stage. The study recommended the necessity of using the list of the environmental values during the process of designing the curricula or developing them plus the necessity of organizing and ordering these values in the curricula of this stage which indicate the integration and the balance between the topics.

The study of Al-Shafi(2003) aimed at identifying the impact of practicing the free environmental activities on developing the primary students' environmental awareness. The study used proposed free environmental activities and a measure for the environmental awareness to be applied over 24 weeks. The results showed an impact to the free environmental activities on raising the experimental group's environmental awareness.

\section{Method and Procedures:}

This study aimed to assess the books of Islamic Sciences and Islamic culture at the secondary level in Jordan in light of contemporary environmental standards, so the study was done to determine community action, and appointed, and its tool as follows:

The study population: The study sample consisted of the same study population, a science books and Islamic culture at the secondary level in Jordan that taught in the academic year 2012/2013, namely:

1. Islamic science and Islamic culture book at the secondary level, "first level".

2. Islamic science and Islamic culture book at the secondary level, "second level".

3. Islamic science and Islamic culture book at the secondary level, "third level".

\subsection{Methodology}

The study methodology: In this study, descriptive analytical method which is based on the study of the phenomenon at the present time and as they really are, which is appropriate to the curriculum and the best for such studies. The study population: The study sample consisted of the same study population, which the Islamic Culture and Islamic sciences books at the secondary level in Jordan that taught in the academic year 2012/2013.

The study's instrument:

To achieve the objectives of the study, the researcher did the following: 
1- Preparing a list of the modern environmental standards through revising related literature to the environmental education in particular and the environment in general plus revising the standards which were prepared by UNESCO, Saudi Meteorology and Environmental Protection association, US Environmental Protection Agency in addition to the EC' standards. For the sake of preparing the instrument, the researchers get benefit of the opinions of some Jordanian academic staff, employees in the Ministry of Environment and some other employees in the Royal Scientific Association.

2- The researchers presented the initial list of the axes and the modern environmental standards to a group of arbitrators consisted of educational lists, university academic staff and others who are interested in the Jordanian curricula. The researchers took into account the arbitrators' notes and opinions and the final copy of the study's instrument consisted of nine axes and 27 modern standards of the environmental education which approved its validity.

The researchers adopted twice the Re-analysis Method within a period of time lasted for three weeks to assure the reliability of the process of analysis by analyzing the content of the books of the Islamic sciences and culture of the secondary stage in Jordan which were taught for the year 2012-2013. After these books were analyzed by one of the researchers, one of the academic staff who is specialized in the curricula of the Islamic studies and methods of teaching them analyzed the content of the books following the same procedures used in the previous analytical process. And to identify the reliability of the analysis, Holsti for analysis was used. Table. 1 illustrates the intercoder and intracoder reliability coofficients.

Table 1. The intercoder and intracoder reliability coofficients

\begin{tabular}{clcc}
\hline N & Axis & Intercede & Intracoder \\
\hline 1 & Resources & 91 & 86 \\
2 & Science \& Technology & 90 & 88 \\
3 & Energy & 94 & 90 \\
4 & Population & 92 & 88 \\
5 & Consumption \& Development Economic, & 91 & 88 \\
6 & Cooperation & 94 & 91 \\
7 & Ethics, Values \& Behavior & 89 & 87 \\
8 & Culture, Notification\& Environmental Enlightenment, & 91 & 87 \\
9 & Legislation \& Censorship & 94 & 89 \\
\hline
\end{tabular}

\subsection{The procedures}

Answering the first question: "What are the modern standards of the environmental education that should be available in the books of sciences and Islamic education of the secondary stage in Jordan and which are taught in the academic year 2012/2013?"

The researchers followed the steps mentioned in the procedures of preparing the study's instrument and the axes and standards concerning this instrument were the answer of the first question. 
Answering the second question: "What is the degree of considering the modern standards of the environmental education in the textbooks of Islamic education, science of the secondary stage in Jordan which is taught in the year 2012-2013?"

The content of the books of Islamic sciences and culture of the secondary stage in Jordan through using the study's instrument to evaluate the modern standards of the environmental education followed in these books as the researcher did the following:

a- Identifying the aim of the analysis which is evaluating the books of Islamic sciences and culture in Jordan for the year 2012-2013 based on the modern standards of the environmental education.

b- Determining the population of the study which consisted of textbooks of Islamic sciences and culture for the secondary stage in Jordan.

c- Determining the category of analysis which nine axes are including 27 standards as it illustrated in the study's instrument.

d- Identifying the unit of analysis which is the sentences and the semi one plus the meaning.

e- Conducting the process of analysis and calculating the frequencies and the proportions or every axis and its standards in every class.

\subsection{Statistical treatment}

The researchers used the appropriate statistical procedures as mean, frequencies and the proportions to collect data concerning answering the study's questions to identify the results and discussing them as follows:

1) Holstein Equation to calculate the reliability coefficient.

2) Frequencies and proportions to calculate books' degree of compatibility to the modern environmental standards.

3) The arithmetic means to calculate the proportion of the Islamic sciences and culture books' compatibility to the modern environmental standards.

\section{Results}

First: results concerning the first question: "What are the modern standards of the environmental education that should be available in the books of sciences and Islamic education of the secondary stage in Jordan and which are taught in the academic year 2012/2013?"

To answer this question, the researchers reviewed the educational literature and came up with the following major axes which include 27 standards for the environmental education in the basic stage: resources, Science \& Technology, Energy, Population, Consumption \& Development Economic, Cooperation, Ethics, Values \& Behavior, Culture, Notification\& Environmental Enlightenment, and Legislation \& Censorship. 
These axes and their standards will be addressed in detail in the discussion chapter.

Second: the results concerning the second question: "What is the degree of considering the modern standards of the environmental education in the textbooks of Islamic education and science of the secondary stage in Jordan which are taught in the year 2012-2013?

After finishing preparing a list of the modern standards of the environmental education that should be available in the textbooks of Islamic science and culture for the secondary stage in Jordan and in light of this list, the content of these textbooks was analyzed. The analysis showed the following results as it is illustrated in tables $2 \& 3$.

Table 2. Frequencies \&proportions of the degree of the compatibility of the textbooks of Islamic science and culture to the modern standards of the environmental education in the secondary stage

\begin{tabular}{llll}
\hline No & Axis & Sum of freq. & Proportion \\
\hline .1 & Resources & 42 & $\% 10.2$ \\
.2 & Science \& technology & 63 & $\% 15.4$ \\
.3 & Energy & 26 & $\% 6.3$ \\
.4 & Population & 12 & $\% 2.9$ \\
.5 & Economic, development, consumption & 19 & $\% 4.6$ \\
.6 & Cooperation & 37 & $\% 9.04$ \\
.7 & Ethics, values ,behavior & 94 & $\% 22.9$ \\
.8 & Culture, notification, awareness & 78 & $\% 19.07$ \\
.9 & Legislations, control & 38 & $\% 9.2$ \\
& SUM & 409 & $\% 100$ \\
\hline
\end{tabular}

Table (2) illustrates the total of the frequencies and the proportions of the degree of the major axis's availability of the environmental education's standards in the books of sciences and Islamic culture for the secondary stage. The seventh axis (Ethics, values ,behavior) was in the first rank with a total of frequencies (94) and with a high proportion(22.9\%) followed by the axis(Culture, notification, awareness) with a total of frequencies (78) and a proportion (19.07\%). Then the axes were respectively as follows :Science and Technology with 63 frequencies and with a moderate proportion (15.4\%), the Resources axis with 42 frequencies and with a low proportion (10.2\%), Legislations, control axis with 38 frequencies and with a low proportion $(9.2 \%)$, cooperation axis with a total of frequencies 37 and with a low proportion (9.04\%), Energy axis with a total of frequencies 26 and with a low proportion $(6.3 \%)$, Economic, development, consumption with a total of frequencies 19 and with a low proportion(4.6\%),Population axis with a low proportion $(2.9 \%)$. 


\section{Macrothink}

International Journal of Education

ISSN 1948-5476

2015, Vol. 7, No. 2

Table 3. Frequencies \& proportions of the availability degree of the modern standards of the environmental education in the books of the Islamic sciences and culture of the three levels

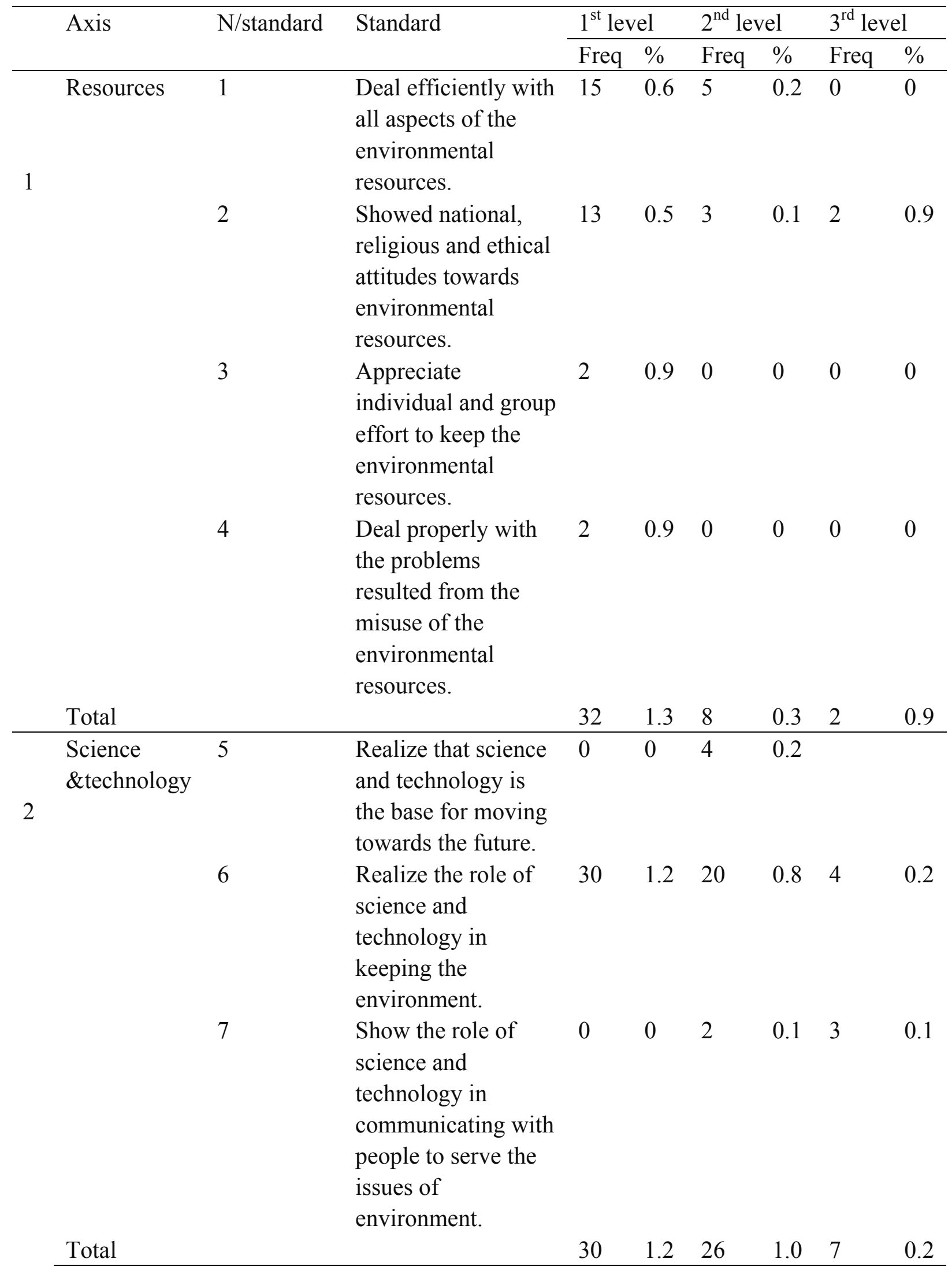




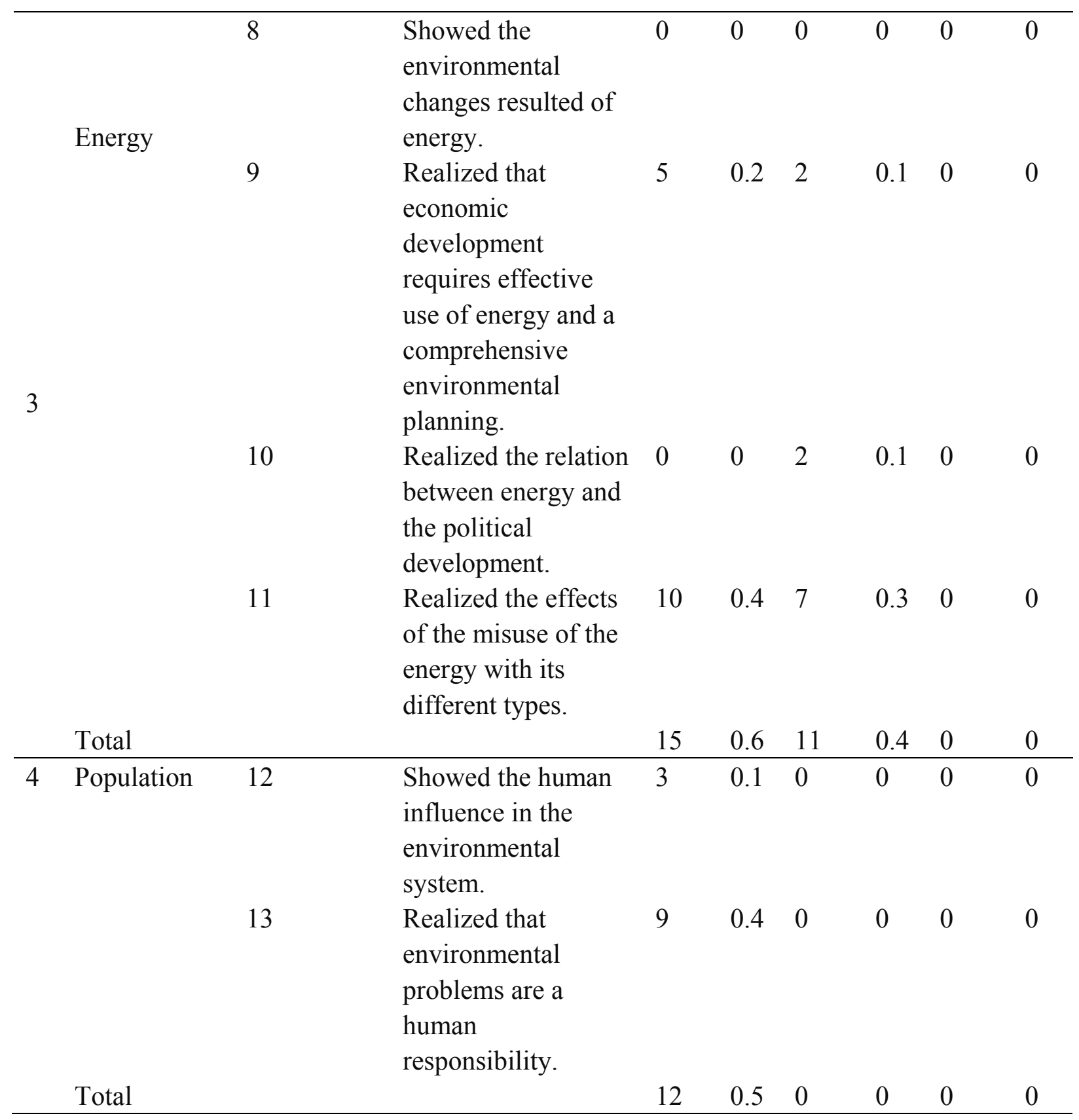


5 Economic \& 14

Development

\begin{tabular}{ll} 
Total & \\
\hline & 16
\end{tabular}

6 Cooperation
Concluded that

economic is

influenced and it

affected the local,

regional and

international

environment.

Showed the

importance of

linking between

economic,

development and

controlling the

consumption.

$\begin{array}{lllllll} & 17 & 0.7 & 2 & 0.1 & 0 & 0 \\ \text { Showed } & 8 & 0.3 & 4 & 0.2 & 2 & 0.1\end{array}$

environmental

protection is a group

responsibility.

Showed the

$15 \quad 0.6 \quad 2$

$0.1 \quad 0$

0

importance of

cooperation in

maintaining the

environment and

believed in the

voluntary work.

Realized the

$4 \quad 0.2 \quad 6$

0.22

0.1

importance of group

work and

cooperation with

others to integrate

the efforts. 
Realize that human 8

0.34

0.24

0.2

Ethics,

7 values,

behavior

Total

Culture,

8 Media

\&Awareness

Realize the effect of 44

depends on his

values, morals and

environmental

behavior.

20

Follow the religion

26

$1.1 \quad 12$

$0.5 \quad 14$

0.6

in keeping and

maintaining the

environment.

$\begin{array}{lllllll}\text { Conclude the role } & 10 & 0.4 & 8 & 0.3 & 8 & 0.3\end{array}$

and the effect of the

family and the

society and their

practices in the

environment.

Media processes in

protecting the

environment and the

role of awareness in

the sustainable

development.

Conclude the role of $\begin{array}{llllll}5 & 0.2 & 5 & 0.2 & 2 & 0.9\end{array}$

Media and

awareness in future

forecast.

Realize the

$\begin{array}{lll}35 & 1.4 & 10\end{array}$

0.49

0.4

importance of

education

concerning

environment's

issues to achieve the

appropriate balance

in the environmental

systems.

$\begin{array}{llllll}43 & 1.7 & 22 & 0.9 & 13 & 0.5\end{array}$




\section{Macrothink Mnstitute"}

\begin{tabular}{|c|c|c|c|c|c|c|c|c|c|}
\hline 9 & $\begin{array}{l}\text { Legislations, } \\
\text { control }\end{array}$ & 25 & $\begin{array}{l}\text { Realize the necessity } \\
\text { of the accurate } \\
\text { control to reduce the } \\
\text { environmental } \\
\text { problems. }\end{array}$ & 28 & 1.1 & 0 & 0 & 0 & 0 \\
\hline & & 26 & $\begin{array}{l}\text { Believe in the } \\
\text { necessity of the } \\
\text { legislation's } \\
\text { flexibility to suit life } \\
\text { development. }\end{array}$ & 5 & 0.2 & 0 & 0 & 0 & 0 \\
\hline & & 27 & $\begin{array}{l}\text { Analyze the } \\
\text { importance of the } \\
\text { regional and } \\
\text { international } \\
\text { cooperation in the } \\
\text { field of legislations. }\end{array}$ & 5 & 0.2 & 0 & 0 & 0 & 0 \\
\hline & Total & & & 38 & 1.6 & 0 & 0 & 0 & 0 \\
\hline & Total Sum & & & 247 & & 105 & 0 & 57 & 0 \\
\hline
\end{tabular}

Table (3) showed the low proportion of the availability of all the standards in the first level (1.3\%) except the twenty fourth $(1.4 \%)$. The tables also showed the low proportion of the availability of all the standards in the second level as well as the third level.

\section{Discussion and Recommendations}

Results concerning the first question: "What are the modern standards of the environmental education that should be available in the books of sciences and Islamic education of the secondary stage in Jordan?" the researchers concluded the following axes and their standards:

First axis: Resources

Environmental resources are the available futures to the human and they are divided into permanent natural resources as solar system and renewed natural resources as the living creatures and the learners' interaction with this axis and its standards aims at showing them the importance of the environmental resources and providing them with knowledge and positive attitudes plus improving the dealing with the environmental problems which are resulted from negative use of the resources. And this axis includes four standards as it is illustrated in the study's instrument.

Second axis: science \& Technology:

This axis discussed the issue that science and technology are strongly related to the processes of the development and they are the basis to move towards better future. The importance of this axis lies in its interaction with the learners that leads to their acquisition of the knowledge, values, and attitudes theoretically and practically to be employed in their lives according to 
their abilities. And this axis includes three standards as it mentioned in the study's instrument.

Third axis: energy

This axis discussed the environmental effects resulted from energy extraction and its use, transfer and transmission. Additionally, the rational use of the energy and maintaining its different resources. The importance of this axis lies in the learners' knowledge of the significance of the energy and its role in our life and realization of the need to look for further and new resources of energy. And the learners' interaction with this axis acquire them skill, knowledge, values and positive attitudes towards dealing the energy and its effect on the environment. And this axis includes four standards as it is illustrated in the study's instrument.

Fourth axis: Population

This axis addresses the relation between population and the environment and it seeks to show the learner that humanity has great effect on the environmental system and it has major role in the environmental problems. It is supposed that the learners' interaction with this axis leads to the learners' acquisition of values, knowledge and positive attitudes to reduce the population problem and its negative effects on the resources and the environment. And this axis includes two standards mentioned in the study's instrument.

Fifth axis: Consumption \& Development, Economic

This axis addresses the mechanism of utilizing the environmental resources to have economic and luxurious development to the people. The learners' interaction with this axis and its standards leads to acquire values and positive attitudes. And this axis includes two standards as it illustrated in the study's instrument.

\section{Sixth axis: Cooperation}

This axis aimed to make the learner aware of the importance of protecting the environment because it is for every one and it will not be developed unless the whole community cooperates. The significance of this cooperation is represented by maintaining and protecting the environment. The learners' interaction with this axis and its standards make them acquire knowledge, values, attitudes and skills to protect the environment and this axis includes three standards as it is illustrated in the study's instrument.

Seventh axis: Ethics, Values \& Behavior

The ethical education is considered one of the most important principles which the environmental education based on. And this axis seeks to let the learner realizes that the continuity of humanity relies of ethics and the values he owns regarding respecting the environment and its maintenance, the strong motives for serving humanity and improving the environment. The learners' interaction with this axis and its standards helps them to acquire values, knowledge and positive attitudes. This axis includes three standards as it illustrated in the study's instrument.

Culture, Information \& Environmental Awareness: 
The importance of this axis lies in the learner's realization of the importance of culture, media and the environmental awareness in maintaining and protecting the environment. And, the learners' interaction with this axis and its standards helps them acquire values, knowledge and positive attitudes towards the different means of media that address environmental issues. This axis includes three standards as it illustrated in the study's instrument.

\section{Legislation \& Censorship:}

This axis examines the effect of the Legislation \& Censorship in protecting the environment. The learners' interaction with this axis and its standards helps them to acquire values, knowledge and positive attitudes towards legislations and the laws. This axis includes three standards as it illustrated in the study's instrument.

Discussion of the second question: "What is the degree of considering the modern standards of the environmental education in the textbooks of Islamic education and science of the secondary stage in Jordan which are taught in the year 2012-2013?

Table (2) illustrates the total of frequencies and the proportions of the of the availability degree of the major axes of the environmental education's standards in the textbooks of Islamic science and culture of the secondary stage as the seventh axis (Ethics, Values \& Behavior)came in the first rank with a total of frequencies (94) and with a high proportion (22.9\%) and the eighth axis was in the second rank with a total of frequencies (78) and a high proportion $(19.07 \%)$ while the second axis (science \&technology) are in the third rank with a total of frequencies (63) and with a moderate proportion (15.4\%) and the first axis( resources) was in the fourth rank with a total of frequencies ( 42 ) and with a low proportion( $10.2 \%)$. And the other axes' order was as follows: the ninth axis (legislations \& control) with a total of frequencies (38) and with a low proportion (9.2\%), the sixth axis (cooperation) with a total of frequencies (37) and a low proportion (9.04\%), the third axis (Energy) with a total of frequencies (26) and with a low proportion (6.3\%), the fifth axis (Economy \& Development \& Consumption) with a total of frequencies (19) and with a low proportion $4.6 \%$ ) and the fourth axis (Population) with a very low proportion (2.9\%).

The results concerning this question showed that the seventh axis (ethics, values \& behavior) and its standards came in the first rank with a high level (22.9\%) and this result may due to the fact that the ethical aspect including the attitudes and positive religious values are the main principles of the Islamic education which seeks to make the learners acquire especially towards the environment. the human continuity in his environment relies on his values and ethics.

And the results concerning this question showed that the eighth axis (culture \&media \&awareness) came in the second rank with a total of frequencies (78) and with a high proportion (19.07\%) in addition to the second axis (science \&technology) which was in the third rank with a total of frequencies (63) and with a moderate proportion(15.4\%). This result may attribute to curricula designers' realization of the strong relation between each of ethics, values, behavior, culture, media, awareness, science and technology. The media, awareness, science and technology are the only way to make the learners achieve and acquire the ethics, values and the behavior. 
While the first axis (Resources) came in the fourth rank with a total of frequencies (42) and with a low proportion (10.2\%) followed by the ninth axis (legislations control) with a total of frequencies (38) and with a low proportion (9.2\%), the sixth axis (cooperation) with a total of frequencies (37) and with a low proportion (9.04\%), the third axis (Energy) with a total of frequencies (26) and with a low proportion (6.3\%) whereas the fifth axis(economy \& development \& consumption) with a total frequencies (19) and with a low proportion $(4.6 \%)$ and the fourth axis (population) was in last rank with a very low proportion ( $2.9 \%)$.

Despite the importance of the first axis( the resources), the ninth axis( legislations\& control), the third axis( energy), the fifth axis(economy \& development \& consumption) and the fourth axis (population, but these axes which related to environment and its protection were neglected and this may due to the traditional perspective of the curricula designers and the issues of these textbooks are compatible with this traditional perspective whereas the modern perspective seeks to plan and design the curricula and the textbooks according to the axes and the standards of the environmental education as they represented the modern attitudes in designing the curricula. Protecting the environment is a group and individual responsibility because everyone owns the environment and the problems of the environment are the human's responsibility; for example, the human caused the pollution and paying attention to the population is a real indication to the situation of the healthy environment. Additionally, the importance of the cooperation in protecting and maintaining the environment is linked with a proper economy which is considered the major sponsor for protecting the environment and the consumption is considered one of the income's component as well as an indicator for the society's luxury. those who work on designing the curricula of Islamic Education should realize the necessity of changing patterned of consumption, leaving imitation and economic fellowship and the students should realize during their study to the curricula of Islamic Education specially in the advanced levels the necessity of faith that Arab World's development can be achieved only by its direct domination of its available energy and utilizing it properly as environment awareness and the students' knowledge of the environmental legislations become a necessity:

1- The designers of the Islamic studies curricula for the secondary stage should take into account the axes of the following environmental educational standards: (legislations\& control), (cooperation), (energy), economy \& development \&consumption) and (population).

2- Conducting similar studies on the curricula of the Islamic studies for the first levels to identify the extent to which these curricula are aware of the standards of modern environmental education.

\section{References}

Abdaladem, A. A. (1999). Islam and Environment. Alexandria, Institution of University Youth.

Al-Alawi, Y, M. (1988). Evaluating the curricula of Islamic Education of the third Secondary 
in Bahrain In light of the stage's objectives and its suitability to solve the students' problems, Unpublished Thesis, College of Education: University of Tanta.

AlBosaidi, Q. (2003). Evaluating the Islamic Education on Oman in light of the modern issues. Unpublished thesis, Education College, Sultan Qaboos University.

Al-Dahir, H., Al-Tayb, A., Al-Badawi, H., \& Al-Asal, k. (1993). Researches in the Islamic education. Cairo, Dar Hikma.

Al-Hamd, R., \& Sabarini, M.S. (1979). Environment and its problems. The national council for culture and Art, Kuwait.

Al-Sawafi, A. (2002). Environmental Values in the textbooks of Geography in the basic stage: analytical study. Unpublished Thesis, Masqat, University of Sultan Qaboos.

Al-Shafi, I, M. (1984). Islamic Education and Its methods of teaching. Kuwait: Falah Library.

Al-Shafi, S, M. (2003). Impact of Practicing Free Environmental Activities on Developing the Environmental Awareness of The Primary Stage's Students. Cairo Journal of Scientific Education, 6(2), 124-143.

Al-Tantawi, R. (2000). Environmental Education: Compulsory Education. Cairo, Dar Nahda Al-Arabia for publishing.

Brody, M, J. (1991). Understanding of Pollution among 4th, 8th and 11th Grade Students. $\begin{array}{llll}\text { Journal of Environmental } & \text { Education, 2(22), 377-384. }\end{array}$ http://dx.doi.org/10.1080/00958964.1991.9943051

Ghanim, H, M. (1997). Enter Of Islamic Studies Researches, Institute Of Scientific Researches And Surviving The Islamic Heritage. Makha Mokarama, University of Om al.Qura.

Gillet, M. (1977). "UNESCO Conference on Environmental Education", Georgia, News Letter with the International Bureau of Education, Unesco, Vol 5, No. 4, December.

Hameeda, E., Arafa, S., Al-Qirsh, H, S., Mohamad \& Al-Qurshi, A. (2000). Teaching social studies in the general Education, 1, Cairo.

Hareb, Saeed Abdullah. Changing the Arab educational curricula and its impact on policy and educators and sociologists. Retrieved from http://www.edueast.gov.sa/vb/lafivevson/index 2006

Hijazi, M. (1995). Delinquents’ child. Lebanon.

Hirash, H. (1995). Analyzing the content of the textbooks of the studying the second stage of the basic education in Algeria according to the standards and the objectives the environmental education, Unpublished Thesis, Algeria, University of Algeria.

Law of the Ministry of education in Jordan. (1994). N(3).

Marashda, H. (1989). Impact of including the environmental dimension in teaching social studies on the students' attitudes towards environment. Unpublished Thesis, Irbid, 
Yarmouk University.

Mo`tamn, M., \& Al-Atrash, H. (2002). A report about Jordan's participation in the international conference of education. Teacher's Message, 41(1), 45-47.

Motaw`, Ibrahim Esmat. (2001). Environmental Education in Arab World. Cairo, DAR fikr arabi.

Qasim, H. (2001). Extent of availability of the environmental education concepts in the textbooks of Arabic, $1^{\text {st }}$ session in the basic education stage in Jordan. Unpublished Thesis, Fashir, University of Fashir.

Qasim,M, J. (2005). Treating the curricula of Islamic EDUCATION in UAE of the concepts of Extremism, fanaticism and terrorism. International Circle, Curricula of religious teaching in Islamic world: challenges and perspectives in Malaysia, (2), 135-137.

Salama, W. (2002). Educational environment of kindergarten baby. Cairo, Dar fikr.

Saleem, M, S. (1976). Basic concepts of environmental education as a reference in the environmental teaching in the general education levels. Cairo, ALECSO.

Shonaq, A, M, H. (2001). Phenomena of Delinquents in Jordan.

Sterile, Walter E. (1977). The Environmental Education National Science, Teachers Association. Washington, P.5.

Todt, D. (1996). "An Investigation of Environmental Literacy of Teachers in South - Central OHIO Using the Wisconsin Environmental Literacy Survey, Concept Mapping and Interviews". Doctoral Dissertation. The OHIO State University, Dissertation Abstracts Service, No. AAC 9544703. WWW.Islam- qa.com/ar/ref p.p1-313/10/2010

UNESCO (1968). International Conference on Public Education. Final Report (Paris).

UNESCO (1978). Environment and development: Basic concepts of the new entrance of environmental education. Cairo, Enesco Press (4).

UNESCO-UNEP (1970). Framework for Environmental Education, International Environmental Education", work Shop held In Belgrade, Yugoslavia 1st October, Environmental Education Report, and December- January.

Wright, B., \& John P.W. (1980). Social Problems ‘First- Edition ‘Canada: Little ‘Brown \& Company Limited ‘Library of Congress Catalog Card No. 79-88192.

Zaid, M, I. (1988). Environmental Concepts And Attitudes In The Textbooks Of Science For The Two Stages; Elementary And Secondary In State Of Bahrain, Unpublished Thesis, Amman, University of Jordan. 


\section{Copyright Disclaimer}

2015, Vol. 7, No. 2

Copyright for this article is retained by the author(s), with first publication rights granted to the journal.

This is an open-access article distributed under the terms and conditions of the Creative Commons Attribution license (http://creativecommons.org/licenses/by/3.0/). 